\title{
THE CONSTRUCTION OF MEANING AND POSITION OF MENTAL DISORDER CHARACTERS IN THREE ROMANCE FILMS
}

\author{
Dite Nursyamsi Mahmutami \\ Universitas Islam “45”, Bekasi, ditenursyamsi@gmail.com
}

\begin{abstract}
This research discusses the representation and discourse which focused on the elements of characterization and narration which is presented by mental disorder character in Silver Linings Playbook (2012), Touched with Fire (2015) and The Other Half (2016). In this research, mental illness is not analyzed as a medical narration but also is one of signifying practices. The approaches of media representation analysis from Simon Cross (2014) and Harper (2008) are used to determine the representation of life experiences and disassemble the emerging discourses. The result indicates that when mental illness is represented in the romantic film, the stereotype about abnormality, rejection, and exclusion still becomes the main structure of the narrative. The romance story that wraps it up still refers to the stereotype. Therefore, those three films can be concluded as a part of dominant statements on abnormality discourse against mental disorder sufferers. In this case, mental disorder sufferers are subjected as a subject that must change. It is because only one choice for mental disorder sufferers to be accepted in society, that is recovery.
\end{abstract}

Keywords: Mental Disorder Character, Discourse, Representation, Film

\section{INTRODUCTION}

A film is one of the popular media which conveys messages and can be a lesson for audiences. It is expected to be able to have an impact on social change. Through film, we can see a character from a certain perspective. Thus, the film is a cultural product and cultural practice that constructs the lives of individuals or communities through storylines that are presented through visual, acoustic, and text signs. Therefore, the film is a representation system that constructs the meaning of an event, experience, or a certain idea.

A film can take on various themes; one of them is mental issues. The film with this theme uses character and story about mental disorder. Although the story based on the genre, there are similarities of mental disorder characters which are always presented as a strange character. The strangeness is the portrayal by appearances, behaviors, and utterances shown by mental disorder characters. They are described differently from normal people which become a stereotype that operates in everyday life.

"Mental disorder is interpreted as an absence or lack of mental health" (Notosoedirjo, 2014:36). So, people with a mental disorder must be treated and cured medically. It shows that mental disorder is a medical narrative. However, the meaning, representation, and treatment of the people and mental disorder cannot be separated from cultural practices. Therefore, mental disorders can be placed as a discourse and study in cultural studies. "if culture is always an aspect of our reality, then to study culture is to be concerned with how we engage with this 
reality, how we make contact" (Highmore, 2016:119). If a mental disorder is a reality that encountered, experienced, and consumed (in the meaning of representation in media and film or everyday conversation) then matters relating to mental disorders are inseparable from cultural practices.

The narrative of mental disorders is signifying practice whose meanings are constructed and raised in popular media. In the form of articles and film media, mental disorders cannot be separated from a series of specific cultural practices. This shows that mental disorders are not just diseases and related to medical matters, but they are also cultural practices.

There are many films which the theme of mental issues. In this research, three mental disorder films are chosen to see representations, discourses, and positions of mental disorder characters. The films are Touched with Fire (2015), The Other Half (2016), and Silver Linings Playbook (2012). Those films are chosen because those have a romantic genre with mental disorder sufferers as the main character. So, it can see how love as the life experience of mental disorder characters appears in these films.

\section{LITERATURE REVIEW}

\section{Madness in Television Documentary}

Simon Cross (2004) researched representation of madness in television documentaries. The representation form is in the form of the dominant icon of insanity. "Images we conventionally associate with madness: wild, unkempt hair; tattered clothing; red-veined, staring eyes; muttered imprecations; fists shaken at "things" that are not there; outspoken dialogues to the different parts of oneself. These are stereotypical conceptions that make it clear how madness is seen: as visible differences of appearance and behavior that demarcate a symbolic boundary between "us" and "them." (Cross, 2004: 119). Documentary films a way of representing the reality of mental illness which is portrayal as endangering the public, having strange behavior, engaging in an unexpected act, and different being abnormal stereotypes that label madness on TV.

In this research, Cross explore the portrayal of three forms of madness in British television documentary. Each program deals with releasing schizophrenic patients into society in order to understand the implications of releasing mental disorder patients from mental hospital. As the result, in panoramic program, schizophrenic sufferers are represented as endangering the public so that they need to be handled by the police (Cross, 2004:205). In an undercover program, someone investigates care policies for homeless schizophrenics (Cross, 2004:207). Patients are described as having strange behavior, but sufferers do not even get proper treatment. This has become an icon of failure to care for the community. By presenting strange humans, the video raises the notion that without medical assistance, schizophrenics will inevitably engage in unexpected, strange and dangerous actions. Finally, in the diary video, schizophrenics are depicted as different people and are labeled based on stereotypes of insanity (Cross, 2004:210). This video is a form of self-representation from the sufferer's life experience.

$\mathrm{TV}$ is at the center of public discourse about what is considered normal. The three programs above are a visual representation that represents the struggles of people with mental disorders. The TV program also illustrates that mental illness along with stereotypical images of abnormalities are inevitable. Therefore, Cross 
says that the challenge of the issues of representation of mental disorder is in rejecting stereotypes of insanity (Cross, 2004:213)

\section{Paradigm Madness in Film and Media}

Stephen Harper (2008) researched the extent of criticism of media about mental illness and whether the critic's paradigm of anti-stigma criticism requires new modifications. The media over-represent people with mental distress as violent (Harper, 2008:170). Many new problems arise while many old stereotypes and discrimination of sufferers still exist. In TV drama and soap operas, Harper observes that the storylines show an awareness of mental disorder theme. The storylines seek to break down a longstanding culture that many sufferers to find it difficult to express their psychological difficulties. Meanwhile, in the documentary, Harper shows that the medium helps ward off stereotype of mental disorder (2008:171) While, he sees the magazine explore the mental health of celebrities (2008:171). The new challenges are the more media represent mental illness in too positive ways (2008:172). However, this shows a lack of trust in the imperfect group (2008:173).

\section{METHOD}

In this research, the theories used are a media representation analysis that is representation analysis by Stuart Hall and semiotic analysis by Roland Barthes and discourse analysis by Michel Foucault. The data are the screen shoot and dialogue of three mental disorder films that are Silver Linings Playbook (2012), Touched with Fire (2015) and The Other Half (2016). The steps of the data analysis are (1) Watched the films, and collected screenshot and dialogue transcription, (2) collected statement by archival analysis to find pattern culture practices of mental disorder (3) categorize the abnormal clothes and expression and behavior when relapsing to analyze the representation of mental disorder characters by representation analysis Stuart Hall and semiotic analysis Roland Barthes. (4) categorize the experience of love and the title's relation to the whole story, (5) analyze the statements to find the discourse which appears and position mental disorder character by discourse analysis Michel Foucault. 


\section{FINDINGS AND DISCUSSIONS}

\section{Silver Linings Playbook (2012): Love Heals Mad Man}

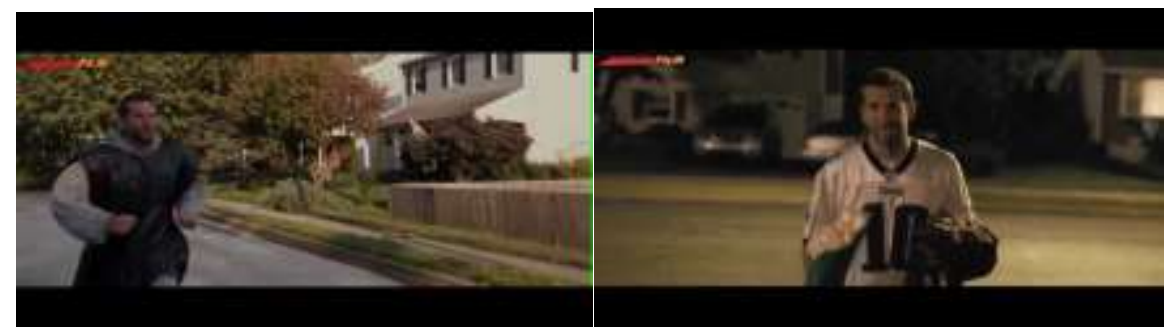

Figure 1: Pat's Clothes in Silver Linings Playbook (00.37.00) and (00.22.58)

In figure 1, Pat as a mental disorder character is represented by wearing abnormal and unacceptable clothes because it is considered strange. He wears a garbage bag that covers his clothes when he exercising and a jersey as a formal dinner outfit. Pat was aware his clothes were not normal, but that made Pat look weird. So, the outfit of mental disorder character is still in dominant stereotype in the form of strange and abnormal.

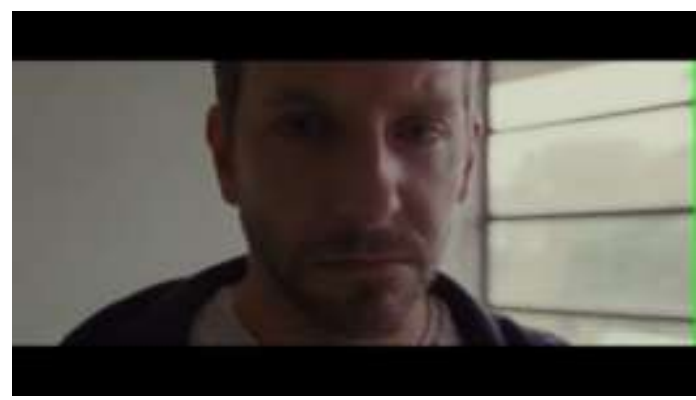

Figure 2: Pat's expression in Silver Linings Playbook (00.01.13)

Pat also showed abnormal expression by often pensive with unexpressive face and blank stares. In figure 2, the expression attached to characterize him as mental disorder sufferers. A pensive with unexpressive face and blank stares connotes the concept of abnormality, madness, and oddity.

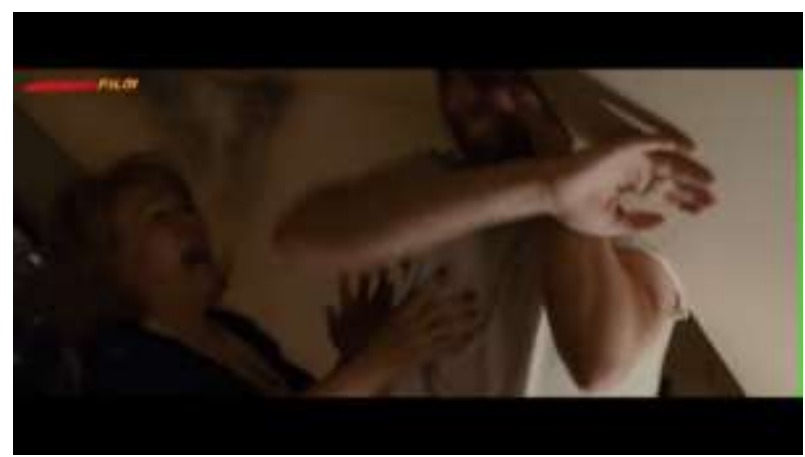

Figure 3: Pat was on rampage in Silver Linings Playbook (00.33.17)

Figure 3 shows that Pat's behavior also indicates the oddity by impulsive act with anger, raging, ruffing object, and hallucination. The unstable emotions connote the concept of abnormality and madness inherent in a mental illness sufferer or Foucault calls mania. This means Pat's behavior presented in the film 
reinforces the dominant stereotypes that emerge about the behavior of mental disorder sufferers.

However, this film presents another side of the dominant stereotype. Pat's love experience becomes the thing that triggers his mental disorder. Nevertheless, love also healed him. The stereotype of abnormality, madness, strange, and unfamiliar become a myth of mental disorder sufferers juxtaposed with myths about romantic romance. Love that blows destruction, or in this case madness, turns to love that heals. Thus, if it is observed by the presence of the character aspect, this film narratives use the dominant stereotype of mental disorder sufferers. But, if it is looked at the whole story, the film's narrative leads to the myths of romance Hollywood-style.

The story of mental disorder and love in this film is related to the title. The silver lining (Merriam-Webster.com, 15 Juli 2020) is an idiom derived from the phrase 'every cloud has a silver lining' which means there is hope from difficulties. While playbook (Merriam-Webster.com, 15 Juli 2020) means a strategy book created to guide teams in a game. The combinations of these titles construct the meaning of strategies that Pat must do as a mental disorder character to see hope and brighter side of his life.

\section{Touched with Fire (2015): Love, Madness, and Creativity}

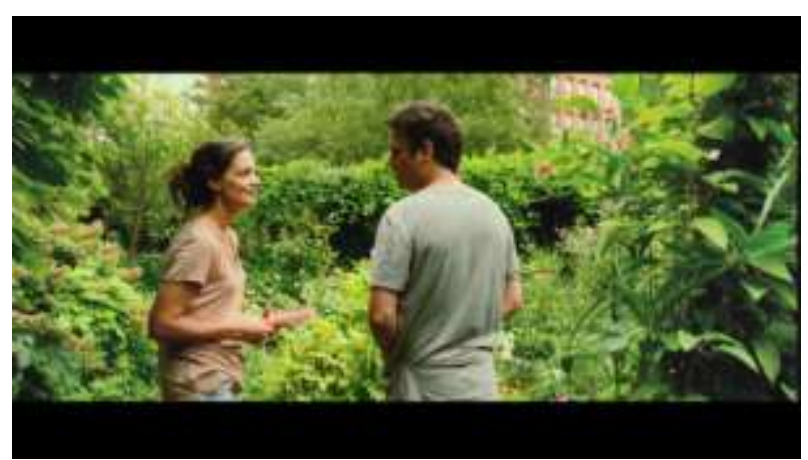

Figure 4: Carla and Marco's clothes in Touched With Fire (01.10.07)

As shown in figure 4, Carla and Marco as mental disorder characters use casual outfit like t-shirts, jeans, jackets, casual dress, and a plaid shirt that are read directed to illustrate their abnormalities. This is because, in the film, most characters are always worn neatly dressed. Besides, Carla and Marco's casual clothes are read directed to reinforce their difference, creativity, and freedom. It also reinforces the stereotypes of Carla and Marco's characters as poets or artists.

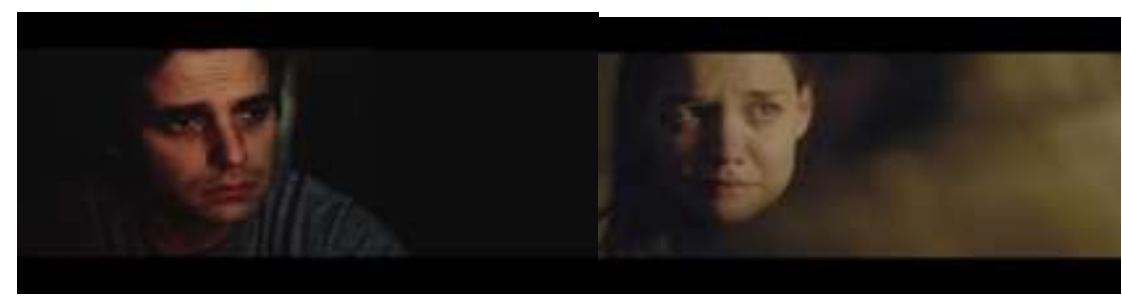

Figure 5: Right Carla cry (01.28.28) and left Marco unexpressive face in Touched With Fire (01.19.18) 
In figure 5, their expressions are also presented with abnormal expressions. Like Pat, Marco's expressions are the things that distinguish it from other characters in the form of pensive with unexpressive face and blank stares that connote to the concept of abnormality, madness, and irregularity. Besides, Carla showed crying and raving expressions that connote the stereotype of women who cry easily because their feeling is soft and like to raise problems.

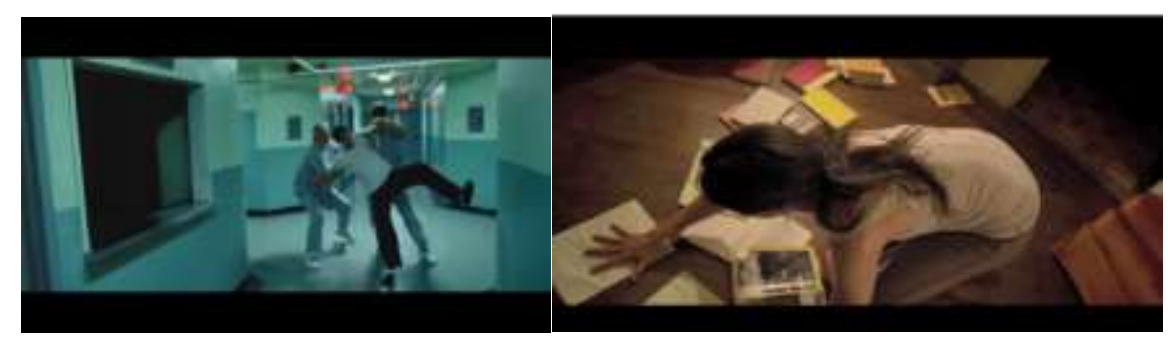

Figure 6: Right Carla wrote poets (00.06.38) and left Marco was rage (00.44.24) in Touched with Fire

The behavior of mental disorders also presented with the abnormality. In figure 6, Carla suddenly woke up and get inspired to write her work in a hurry. Then, Marco did the things that disturb public order such as distributing pamphlets, writing graffiti about the end of the world, and climbing buildings illegally. The behavior and thoughts were considered abnormal and unusual. It is because they can suddenly throw tantrums, act impulsively, and hallucinate. In medical discourse, it is read that the behavior and thoughts are the things that distinguish them from normal characters. That connotes the concept of abnormalities and madness inherent in mental disorder characters. So, the film strengthens and associated with the dominant stereotype about behavior and thoughts of mental disorder sufferers. On the other hand, if they read in the context of art, behavior, and thoughts are part of the creative process. The craziness, hallucinating, and alienating mindset are the behavior of a creative artist in the art context.

In this film, Carla and Marco are involved in a romantic relationship that exacerbates their mental disorder. They fall in love because of the same thoughts and adore their diseases. This film presents love that conquers everything. However, this film also presents the dominant stereotype about fellow mental disorders cannot be together. The experience of love in a romantic story leads to Hollywood romance stories, but this film also leads to the dominant narrative that fellow mental sufferers would endanger one another because they cannot always maintain their emotions.

The title of this film also relates to the story. The film was inspired by a similar title book by Kay Redfield Jamison. The book tells us that there is only a slight difference between genius and creativity with mania or madness. In this film, Carla and Marco are told as poets who have abnormal behavior and in accordance with medical knowledge which shows bipolar disorder symptoms. 


\section{The Other Half (2016): Childish Love of Delirium Girl}

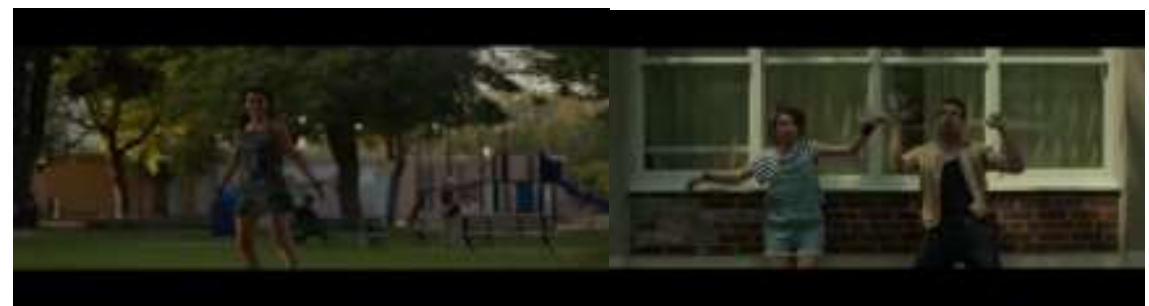

Figure 7: Emily's floral dress (00.12.32) and Emily's jumpsuit (00.20.55) in The Other Half

Emily, in figure 7, wore outfit in the form of dresses, jumpsuit jeans, and t-shirts. Emily's clothes as a mental disorder character is read indicate her childish. The outfit connotes the stereotype of childishness, abnormal and unusual about mental disorder sufferers. This is reinforced by the scene that shows Emily is playing with children.

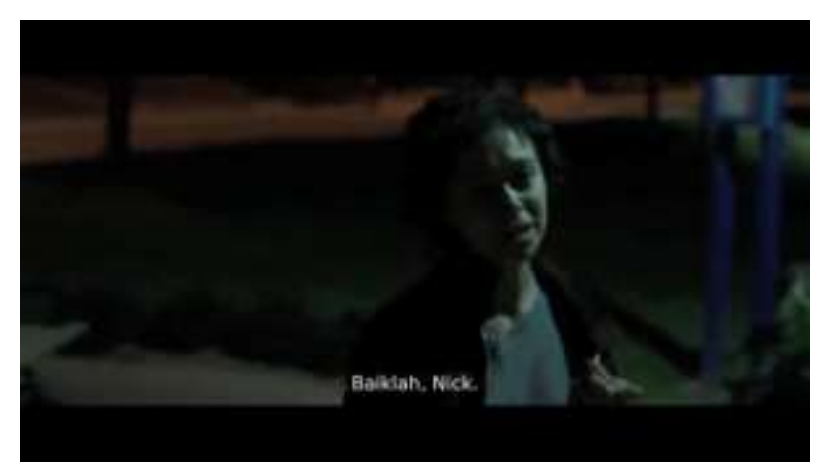

Figure 8: Emily was crying in The Other Half (01.34.30)

In addition, figure 8 shows Emily's expression, crying and babbling. Even though she was persuaded by the people around her, she still did not believe and blamed them. Crying is a way of woman mental disorder characters overflows their hidden emotions. So, the expression is related to the dominant stereotype of mental disorder sufferers.

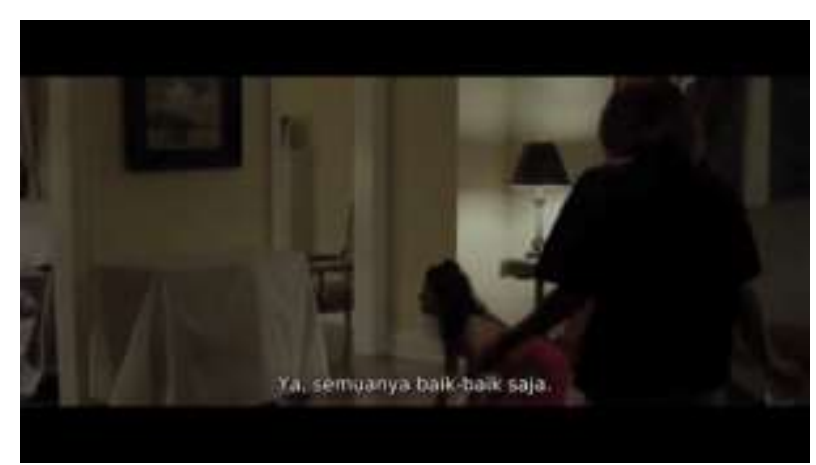

Figure 9: Emily was crawling around the house in The Other Half (00.34.28)

Emily's behavior is also described as abnormally. In figure 9, Emily looks very excited, babbling, and cannot be motionless. When his father told her to calm down, she instead jumped and ran around the house. Emily's behavior leads to stereotyping about mental disorder sufferers. Enthusiastic, babble, and not calm connotes the concept of abnormality ad childishness that is inherent and attached 
to mental disorder sufferers. The presentation of the abnormal character is directed at the stereotype construction of a mental disorder sufferer called mania. Thus, Emily's behavior presented in the film reinforces the dominant stereotype of mental disorder sufferers' behavior.

Like two previous films, this film also presents a love story with a stereotype narrative of romance Hollywood genre. This film narrates love at first sight and childish love. Moreover, this film also presents a destructive and unpleasant love story but fun for the main characters. It reads that the love experience of a mental disorder character would trigger the disease. Destructive love in this case exacerbates mental disorder and unapproved or harm love leads to the dominant stereotype that love can be dangerous and endanger the mental disorder characters.

\section{Discussions}

Those three films show patterns regarding representations and discourses. The patterns include the presentation of clothing, expression, and behavior; discourses that appear in the film include the experience of love and treatment constructed by the knowledge and stereotype that are presented. The presentation of clothing, expression, and behavior of three films above is read as part of signifying practices on the meaning of mental disorder sufferers. The outward appearance of mental disorder characters underlies meanings and definitions by making them strange, different, and dangerous. Although in the daily context people who dress, look and behave as in the explanation above does not mean they have a mental illness, but clothing, expression, and behavior in this film connote an abnormality, madness, and irregularity. The signifying practices construct the meaning of the mental disorder character in what Foucault calls as unfamiliar and abnormal.

Mental issues are seen as a discourse because there are statements that refer to the subject and treatment that is applied in mental disorder sufferers. In the film, the statements come through narrative elements such as character or characterization, plot, narration, and stereotype about mental disorder. In Silver Linings Playbook (2012), the statements are presents through the treatment of mental disorder characters in medical discourse so the character is positioned in medical discourse. However, medical treatment is not a dominant discourse because Pat's recovery is also driven by the presence of a love story that changed his past. Nevertheless, this film remains legible in its position as part of the dominant narrative in the form of changing the disorder to normal. In Touched With Fire (2015), statements of mental disorder present through the treatments in medical discourse. The film also presents a narrative of mental disorder that blurred with the narrative of art. However, romantic discourse does not function as a healer. The fear of hurting each other leads to the end of the love period between two mental disorder characters. The separation of the two mental disorder characters is a symbol of those who are forced to accept and acknowledge that they are subject to the abnormality discourse. Therefore, this film is positioned on the dominant narrative about mental disorder. In The Other Half (2016), statements about mental disorder arise through the presentation of life and behavior of mental disorder character which goes along with stereotypes of abnormality and madness. A romantic story in this film is also not presenting a hope of healing or acceptance. 
Based on the patterns can be summarized that in those romance films, mental disorder sufferers did not have another choice to be accepted and acceptable by society. And the choice is only recovered.

\section{CONCLUSIONS}

Mental disorder characters are always represented in the dominant narrative in the form of abnormality, madness, and oddity both in outward appearance and in the experience of love. This shows the old stereotype and discrimination of mental disorders still appearing in the film by portraying mental disorders in strange, different, and dangerous ways. On the other hand, some discourses surround mental disorder characters that opposing. Each discourse defines, forms different concepts and mentions and forms the position of the mental disorder characters as mental disorder sufferers. In the romantic discourse, mental disorder characters are positioned as normal people who experience love while in medical discourse they are positioned as mental disorder sufferers. Thus, mental disorder sufferers cannot be separated from the dominant narrative of mental disorders where there is no other choice except recovered. Even though mental disorder characters seem to be given an alternative narrative in the form of love, they are separated by their own decisions and destiny. Then, mental disorder sufferers must recover or become normal to enter and be accepted into the normal narrative.

\section{REFERENCES}

\section{Book}

Abrams, M. H., \&Harpham, G. G. (1999). A Glossary of Literary Terms 7th Edition.

Barthes, R. (1968). Elements of semiology. Macmillan.

Barthes, R. (2015). Mythologies. Le Seuil.

Chandler, D. (2017). Semiotics: the basics. Taylor \& Francis.

Coleborne, C. (2020). Why Talk about Madness?: Bringing History Into the Conversation.

Springer Nature.

Foucault, M. (2013). Archaeology of knowledge . Hoboken.

Foucault, M. (1979). Discipline and punish [1975]. na.

Foucault, M. (1988). Madness and civilization: A history of insanity in the age of reason. Vintage.

Highmore, B. (2016). Culture, Routledge.

Jamison, K. R. (1996). Touched with fire.Simon and Schuster.

Notosoedirdjo, M., \&Latipun. (1999). Kesehatan mental: konsepdanpenerapan. UPT PenerbitanUniversitasMuhammadiyah Malang.

Mills, S. (2003). Routledge Critical Thinkers: Michel Foucault. London: Rouledge.

Saukko, P. (2003). Doing research in cultural studies: An introduction to classical and new methodological approaches.Sage.

Williams, R. (1983). Culture and society, 1780-1950.Columbia University Press. Journal Article

Cross, S. (2004). Visualizing madness: Mental illness and public representation. Television \& New Media, 5(3), 197-216.

Foucault, M. (1982). The subject and power. Critical inquiry, 8(4), 777-795. 
Hall, S. (1997). The work of representation. Representation: Cultural representations and signifying practices, 2, 13-74.

Harper, S. (2008). Understanding mental distress in film and media: a new agenda?. The journal of the Royal Society for the Promotion of Health, 128(4), 170-174.

\section{Internet Sources}

Cambridge (n.d).Other Half.In dictionary.cambridge.org dictionary.Retrieved July $18, \quad 2020, \quad$ from https://dictionary.cambridge.org/dictionary/english/other-half

Merriam-Webster.(n.d.).Playbook.In Merriam-Webster.com dictionary. Retrieved July 15, 2020, from https://www.merriamwebster.com/dictionary/playbook

Merriam-Webster.(n.d.).Silver lining.In Merriam-Webster.com dictionary. Retrieved July 15, 2020, from https://www.merriamwebster.com/dictionary/silver\%20lining 